\title{
Development of a RP-HPLC Method for Separating and Quantifying Muscimol in Different Developmental Stages of the Fungus Amanita muscaria
}

\author{
Emersón León Ávila (iD) and James Guevara-Pulido \\ Universidad El Bosque, Química Farmacéutica, INQA Research Group, Av Cra 9 No. 131A-02, Bogotá 110121, Colombia \\ Correspondence should be addressed to James Guevara-Pulido; joguevara@unbosque.edu.co
}

Received 25 August 2020; Accepted 4 November 2020; Published 20 November 2020

Academic Editor: Murat Senturk

Copyright (c) 2020 Emersón León Ávila and James Guevara-Pulido. This is an open access article distributed under the Creative Commons Attribution License, which permits unrestricted use, distribution, and reproduction in any medium, provided the original work is properly cited.

\begin{abstract}
A simple RP-HPLC method was designed for the quantification of muscimol (5-(aminomethyl)-isoxazol-3-ol) present in five aqueous extracts of Amanita muscaria each from a different developmental stage. Results show that the maximum concentration of muscimol $(1,210 \mathrm{mg} / \mathrm{ml})$ was found in the young mushroom stage of development. Moreover, it was also found that this concentration progressively decreases as the fungus ages. The developed method is a simple but effective method for the quantification of muscimol, a widely important metabolite for the pharmaceutical industry as a possible treatment for tardive dyskinesia and Parkinson's disease.
\end{abstract}

\section{Introduction}

Amanita muscaria, commonly known as "fly agaric" or "fly amanita", is one of the best known psychoactive mushrooms in the world due to its psychotropic properties [1]. This fungus is distinguished by a bright red cap featuring small white warty spots, and it is generally found in Europe, Africa, Asia, and the Americas. In Colombia, it was introduced as a symbiont with pine and eucalyptus trees [2]. The main psychoactive constituents of this basidiomycete are neurotoxins ibotenic acid (IBO) and muscimol (MUS), both of which are of interest due to their hallucinogenic and pharmacological properties [3]. Currently, medical research has focused on the use of MUS as GABAA receptor agonists as a possible treatment for tardive dyskinesia and Parkinson's disease [4].

Several studies have sought to identify and quantify various compounds present in this fungus such as muscarine, bufotenin, muscimol (Figure 1), ibotenic acid [5], muscazone, amatoxins, and phallotoxins [6] by use of analytical techniques including paper chromatography [7], zone capillary electrophoresis, HPLC, and GC/MS [8].
HPLC specifically has been described as a reliable tool for the identification and quantification of MUS and IBO. One study quantified both analytes by derivatizing them with dansyl chloride (DNS-Cl) [9], while another study described a method based on the interaction of sensitive ions which allowed for the simultaneous detection of IBO and MUS [10].

Considering that most available methods for the quantification of muscimol require a chemical transformation of the analyte, the following study proposes a simple derivatization-free, RP-HPLC-based method that allows for the quantification of muscimol (MUS) in aqueous extracts of different developmental stages of A. muscaria. Additionally, this method provides a way of identifying which developmental stage of A. muscaria will yield the highest concentration of MUS in order for it to be used as a GABAA receptor agonist.

\section{Experimental}

2.1. Muscimol Extraction. A standard sample of solid muscimol and Sigma HPLC grade methanol (St. Louis, MO, USA), as the solvent for the mobile phase, were acquired via 




FIGURE 1: Muscimol (5-(aminomethyl)-isoxazol-3-ol).

"Suministros Analiticos S.A.A de Colombia" as Toronto Research Chemicals distributor.

For this study, an array of Amanita muscaria samples were collected in Bogota-Colombia (lat-long coordinates: 4.707953, -74.026984; altitude: 2577.694 m.a.s.l), which were then classified according to their developmental stage: button stage, young mushroom stage, and mature mushroom stage [11].

First, samples were dried in order to guarantee their quality, avoid microbial contamination, and promote the decarboxylation of IBO to obtain MUS [12], as shown in Figure 2.

Then, samples were lyophilized and mechanically fragmented to promote the liquid extraction of muscimol using water as the solvent, which yielded a complex matrix of MUS and other compounds. Finally, a sonication pretreatment was carried out before extraction via HPLC.

2.2. Muscimol Separation from the Matrix. Muscimol is a polar molecule that exhibits high solubility in water; therefore, the most suitable technique to work with was reversed-phase chromatography (RP-HPLC).

The first trials were carried out with a standard solution of MUS and an aqueous extract of A. muscaria obtained from approximately $1 \mathrm{~g}$ of lyophilized fungus and $10 \mathrm{~mL}$ of water as described in the previous section. Retention times, peak symmetry, repeatability, and reproducibility were analyzed in order to understand the complexity of the matrix.

Considering that the retention time using a C18 column was appropriate, that at $256 \mathrm{~nm}$ the analyte was welldetected, and that the time/area showed good reproducibility, it was deemed that the method could be designed evaluating only variables like flow rate and polarity of the mobile phase.

Thus, trials to determine the best mobile phase were performed. Given that the polarity of the functional groups present in the analytes determines the elution order of the compounds and recognizing the presence of hydroxy and amino groups in MUS, the retention times were expected to be short. Since the elution order can be modified by changing the polarity of the mobile phase, the proportion of water to "organic modifier" (methanol) was adjusted, to find the optimum polarity of this phase in regard to the retention factor $\left(k^{\prime}\right)$ as such: $\mathbf{H}_{\mathbf{2}} \mathbf{O} / \mathbf{M e O H}: \mathbf{3} / \mathbf{1}, 3.5 / 1,4 / 1$, 19/1, 49/1.

However, increasing the concentration of methanol decreases the retention time of the whole sample indicating an overlap of peaks, which suggests that increasing the organic portion of the mobile phase is an infeasible



FIgURE 2: IBO transformation into MUS through drying-mediated decarboxylation [3].

approach for the separation of the matrix. This can be explained by the fact that, according to Meyer, v. R., the retention factor $\left(k^{\prime}\right)$ in RP-HPLC decreases when the organic portion of the mobile phase is increased [13]. On the other hand, increasing the water content of the mobile phase increased the retention time and allowed for the separation of the MUS peak, which was contrasted with, and then confirmed by the peak from the MUS standard solution. Consequently, it was established that the best mobile phase was constituted by a $49 / 1$ ratio of $\mathrm{H}_{2} \mathrm{O} / \mathrm{MeOH}$ (i.e., using $2 \%$ of $\mathrm{MeOH}$ and the rest water).

Now, in order to use the least amount of mobile phase while decreasing the retention times in an effort to make the quantification method more efficient, the ratio of the mobile phase was maintained throughout, but the flow rate was adjusted by $0.1 \mathrm{~mL} / \mathrm{min}$ from $0.100 \mathrm{~mL} / \mathrm{min}$ to $2.000 \mathrm{~mL} /$ $\min \quad(0.100 \mathrm{~mL} / \mathrm{min}, \quad 0.200 \mathrm{~mL} / \mathrm{min}, \quad 0.300 \mathrm{~mL} / \mathrm{min}$, $0.400 \mathrm{~mL} / \mathrm{min}$, etc). After examining the resultant chromatograms, it was determined that greater flow rate results in shorter retention times but also results in overlapping peaks and an inferior symmetry of the MUS standard solution peak. Therefore, it was concluded that the best-suited flow rate is $0.10 \mathrm{~mL} / \mathrm{min}$. All trials were carried out with an injection volume of $10 \mu \mathrm{L}$, and no widening of the standard peak was observed.

2.3. Calibration Curve. Once the most favorable chromatographic conditions were determined for MUS separation, solutions made up of different concentrations of the standard MUS solution (1.54, 1.00, 0.77, 0.4620, 0.3080, $0.154,0.0770,0.0462$, and $0.0304 \mathrm{mg} / \mathrm{mL}$ ) were injected into a Shimadzu HPLC (Japan, Prominence-i model LC 2030) at $256 \mathrm{~nm}$, with an Ultra Aqueous (AQ) C18 column and a water-methanol $(98: 2)$ mobile phase at a flow rate of $0.1 \mathrm{~mL} /$ min. Subsequently, a calibration curve was plotted (Figure 3), and areas under the curve were calculated. Overall, five series of each standard solution were analyzed in order to verify reproducibility and to carry out a statistical analysis of the results.

According to Figure 3, the calibration curve appears adequate for estimating the concentrations of the compounds present in the matrix since it shows linearity which, in turn, suggests that the method is reliable in its ability to obtain directly proportional results with the analyte concentration in the solutions for the quantification of muscimol at the previously mentioned developmental stages of Amanita muscaria. 




FIGURE 3: Calibration curve of muscimol.

\section{Results and Discussion}

After determining the most favorable chromatographic conditions and building the calibration curve, solutions of the samples of fungi were injected into the RP-HPLC. Quantification is carried out by adding a known amount (twice the analytical concentration) of the standard MUS solution to each sample, allowing it to obtain the approximate concentration of the analyte in a given sample, as shown in Figure 4. Results show that the average retention type for the MUS peak was $5.622 \mathrm{~min}$.

Later, samples were classified according to the development of the basidiocarp in the following matter: sample 1 corresponds to fungi in the button/egg stage, sample 2 includes fungi with convex caps, sample 3 corresponds to fungi that feature a less convex cap, and samples 4 and 5 include fungi in their mature mushroom stage, characterized by a flat basidiocarp. In this case, the MUS peak presented an asymmetric behavior, so the use of the factor $\mathrm{As}_{5 \%}=\mathrm{B}^{\prime} / \mathrm{A}^{\prime}$ was necessary in order to determine with greater accuracy the area under the curve and avoid future misquantifications. After analyzing all samples thrice, the areas under the curve of each chromatogram were obtained, where it can be observed that sample 3 contained the greatest concentration of MUS, as shown in Table 1.

Based on the results above, it can be inferred that the concentration of muscimol varies according to the developmental stage of the fungus. The concentration of MUS is significantly greater in sample 3, which indicates that the concentration is disproportional to the growth stage of the fungus. There are many factors that influence the growth of fungi such as temperature, $\mathrm{pH}$, soil nutrients, light, and oxygen concentration. Under the conditions in which the fungus was collected for this study, where the highest concentration of MUS was found in the young mushroom stage where the fungus is bigger and therefore more visible to predators, it can be deduced that the increase in IBO and MUS concentrations act as a defense mechanism which helps this species survive into adulthood [14]. Additionally, this stage in development is also known as the stagnant growth stage where development declines and toxins are most accumulated.

Considering that the calibration curve suggests that this method provides reliable results, it can be argued that this is also an exact method since adding the known amount of the standard MUS solutions to the samples, which might contain only small traces of MUS, yielded acceptable recovery percentages. Therefore, it can be stated that, with



Figure 4: Muscimol chromatogram from Amanita muscaria samples also featuring the standard sample of MUS.

TABLE 1: MUS concentration in samples of the developmental stages of the fungus.

\begin{tabular}{lccc}
\hline $\begin{array}{l}\text { Sample } \\
\text { number } \\
\text { lyophilized }\end{array}$ & $\begin{array}{c}\text { Mass } \\
(\mathrm{g})\end{array}$ & $\begin{array}{c}\text { Muscimol } \\
\text { concentration } \\
(\mathrm{mg} / \mathrm{mL})\end{array}$ & $\begin{array}{c}\text { Muscimol } \\
\text { recovery } \\
\text { percentage }(\%)\end{array}$ \\
\hline 1 & 7.365 & 0.079 & 1.07 \\
2 & 12.309 & 0.231 & 1.87 \\
3 & 33.883 & 1.210 & 3.57 \\
4 & 38.005 & 0.486 & 1.27 \\
5 & 43.169 & 0.341 & 0.78 \\
\hline
\end{tabular}

different concentrations of the standard MUS solutions, similar recovery percentages should be obtained.

\section{Conclusion}

An RP-HPLC method was designed for the separation and posterior quantification of muscimol from aqueous extracts of A. muscaria. The conditions for this method include an Ultra Aqueous (AQ) C18 column, a water-methanol $(98: 2)$ mobile phase at a flow rate of $0,1 \mathrm{~mL} / \mathrm{min}$, at $256 \mathrm{~nm}$. The average retention time for MUS was $5.6 \mathrm{~min}$, and the highest concentration of MUS, $1,210 \mathrm{mg} / \mathrm{mL}(3,57 \%$ of sample weight), was found in the young mushroom stage of development of the fungus Amanita muscaria.

\section{Data Availability}

No data were used to support this study.

\section{Conflicts of Interest}

The authors declare no conflicts of interest.

\section{Acknowledgments}

This work was carried out by the INQA Research Group and was funded by the Departamento de Química at Universidad El Bosque. This research was funded by Universidad El Bosque Departamento de Química.

\section{Supplementary Materials}

Annex 1. Chromatogram of the standard solution of muscimol. Annex 2. Chromatogram of fungus extract at $256 \mathrm{~nm}$. Annexes 3 and 4. Chromatograms of fungus extract and 
MUS standard solution each with a different mobile phase flow rate. Annexes 5, 6, and 7. Chromatograms of fungus extract and MUS standard solution, each with a different water- $\mathrm{MeOH}$ ratio. (Supplementary Materials)

\section{References}

[1] M. R. Jacobs and K. O. Fehr, Drugs and Drug Abusep. 489, 2nd edition, Addiction Research Foundation, Toronto, Canada, 1987.

[2] A. E. Franco-Molano, "A new species of macrolepiota from Colombia," Actualidades Biológicas, vol. 21, pp. 13-17, 1999.

[3] J. N. Miller and J. C. Miller, Estadística Y Quimiometria Para Química, Prentice Hall, Upper Saddle River, NJ, USA, 4a edition, 2002.

[4] J. Servando, M. Medel, E. Gasca et al., "Receptor GABAA: implicaciones farmacológicas a nivel central," Archivos de Neurociencias, vol. 16, no. 1, pp. 40-45, 2011.

[5] A. Poliwoda, K. Zielińska, M. Halama, and P. P. Wieczorek, "Determination of muscimol and ibotenic acid in mushrooms of amanitaceae by capillary electrophoresis," Electrophoresis, vol. 35, no. 18, pp. 2593-2599, 2014.

[6] H. E. Hallen, G. C. Adams, and A. Eicker, "Amatoxins and phallotoxins in indigenous and introduced South African Amanita species," South African Journal of Botany, vol. 68, no. 3, pp. 322-326, 2002.

[7] R. G. Benedict, "Chemataxonomic relationships among the Basiodiomicetes," Advances in Applied Microbiology, vol. 13, pp. 1-23, 1970.

[8] K. Tsujikawa, H. Mohri, K. Kuwayama et al., "Analysis of hallucinogenic constituents in amanita mushrooms circulated in Japan," Forensic Science International, vol. 164, no. 2-3, pp. 172-178, 2006.

[9] K. Tsujikawa, K. Kuwayama, H. Miyaguchi et al., "Determination of muscimol and ibotenic acid in amanita mushrooms by high-performance liquid chromatography and liquid chromatography-tandem mass spectrometry," Journal of Chromatography B, vol. 852, no. 1-2, pp. 430-435, 2007.

[10] M. C. Gennaro, D. Giacosa, E. Gioannini, and S. Gioannini, "Hallucinogenic species in amanita muscaria. Determination of muscimol and ibotenic acid by ion-interaction HPLC," Journal of Liquid Chromatography \& Related Technologies, vol. 20, no. 3, pp. 413-424, 1997.

[11] C. Alexopoulos, C. Mims, and M. Blackwell, Introductory Mycology, Wiley, Hoboken, NJ, USA, 4th edition, 1996.

[12] D. Michelot and L. M. Melendez-Howell, "Amanita muscaria: chemistry, biology, toxicology, and ethnomycology," Mycological Research, vol. 107, no. 2, pp. 131-146, 2003.

[13] V. R. Meyer, Practical High-Performance Liquid Chromatography, Wiley, Hoboken, NJ, USA, 5a edition, 1999.

[14] D. P. Sánchez and F. Marmolejo, Nutrición Y Crecimiento. Microbiología. Aspectos Fundamentales, Universidad Nacional, Bogotá, Colombia, 2000. 